\section{Teenage pregnancy contextualized: understanding reproductive intentions in a Brazilian shantytown}

\author{
Gravidez na adolescência em contexto: \\ entendendo intenções reprodutivas \\ em uma favela brasileira
}

Karine Alves Santos 1

\section{Introduction}

1 Postgraduate Programme in Anthropology, Environment and Development, University College London, London, U.K.

Correspondence

K. A. Santos

Postgraduate Programme in Anthropology, Environment and Development, University College London.

Gower Street, London

England. WCIE 6BT, U.K.

karine.flynn@hotmail.com

\section{Abstract}

This paper presents the results of a socio-anthropological study with women from a low-income community in Belo Horizonte, Minas Gerais State, Brazil. Through the use of qualitative methods it looks at teenage pregnancy from the young mothers' perspective and the contribution of their socioeconomic environment. It shows the importance of different actors in their fertility decision and identifies contradictory cultural norms that recriminate teenage sexual activity while seeing motherhood as a ritual of passage to adulthood. Following criticisms of insufficient family planning programs and negative health and economic outcomes for the lives of youngsters, the paper argues that motherhood stands as a successful activity through which they fulfill the collectively recognized ideal of womanhood, also carrying a sense of achievement in an environment where lack of opportunities prevail long before pregnancy occurs. Improving formal knowledge and economic well-being are possible solutions to provide these girls with goals that go beyond parenthood while within reach of their economic reality.

Pregnancy in Adolescence; Contraception; Family Planning
Women have traditionally married and had their first child at a young age in many parts of the world ${ }^{1}$. Recently, however, teenage sexuality and pregnancy have been framed as a social problem, whose negative outcomes for the lives of adolescent women (e.g. higher exposure to STDs including HIV/AIDS, high subsequent fertility, truncated education, economic disadvantage, etc) have been widely used to justify the need for public intervention and expansion of family planning programs to target the issue $2,3,4,5,6$. The assumption that teenage pregnancy is frequently unwanted or unplanned suggests that one of the causes may be the insufficiency or inadequacy of family planning programs 7,8 . However, despite the availability and free distribution of contraceptive methods in some regions, the reluctance to use them ${ }^{9,10}$, and persistent age-specific fertility rates point at flaws in a model that analyzes fertility intentions as a direct result of contraceptive use, furthermore ignoring cultural norms and ideals of motherhood and family size.

Brazil has presented declining fertility levels since the early 1970s, but adolescent fertility is still considered to be an increasing phenomenon, especially among the poor strata 11 . In a culture where motherhood is desirable and central to womanhood 8,12 , this study aims to 
investigate whether adolescent females consider pregnancy to be a problem, analyzing their discourse in the light of their socioeconomic scenario and consequent aspirations while investigating the role of different actors in their decision-making process. Guided by the hypothesis that motherhood can present itself as a milestone and transition into womanhood, this research takes socio-cultural aspects into consideration to understand local views in teenage pregnancy and how these views might affect girls' attitudes towards contraception and childbearing. In order to attempt to answer that question I chose to investigate what appears to happen in a shantytown within the metropolitan area of the city of Belo Horizonte, Minas Gerais State, Brazil, by making use of qualitative methods for data collection such as participant observation, in-depth interviews, and focus group discussions.

\section{Methodology}

The research site chosen was Vila Novo São Lucas, located within the Metropolitan area of Belo Horizonte, with a population of around 4,000 inhabitants spread over $151.326 \mathrm{~m}^{2}$. Vila Novo São Lucas is one of the six slums that together form the "Aglomerado da Serra" - Belo Horizonte's biggest settlement, currently housing over 50,000 people 13 .

For the purposes of this study qualitative methods were used for data collection, which consisted of interviews with key informants (e.g. local church priests, the local school's Head Teacher, the doctor and nurse/social worker from the health center), in-depth interviews with young mothers and mothers of teenage mothers, participant observation and field notes, as well as focus group discussions.

Reflective analysis was an on-going process taking place throughout the data collection. And although interview guides were developed beforehand, new ways of approaching unforeseen topics were developed and the interview guides were refined accordingly.

In-depth interviews were conducted as follows: with key informants who are local community figures, 10 young mothers who were under 18 at childbirth, 10 young mothers who had their first child after age 18, and 5 mothers to teenage mothers. The interviews were made in various locations where privacy was possible, recorded then transcribed, and the profiles were later translated to English. Consent of the participants was requested and given. This research followed all the necessary ethical principles and was approved by the University College London Research Ethics Committee.

The open-ended interviews were conducted using a general guide approach intended to ensure that the same general areas of information were collected from each interviewee, while still allowing a degree of freedom and adaptability in obtaining the information.

Having had case-oriented and comparative perspectives, this research made use of content analysis and grounded theory 14 , the latter being used to analyze the corpus of data and identify different variables and their interrelationships.

Coding started with full transcription of the interviews in an effort to recognize key words or sentences, incorporated by field notes to identify emerging patterns, allow comparisons, and provide guidelines for collecting additional data.

The next step was to organize the responses into labeled clusters, furthermore breaking the discourse of the participants and creating categories, or codes, which could be compared and contrasted. Through systematic analysis and comparison of data, the number of codes were organized in a way that showed the relationship among them, thus giving rise to a core category representing hypothetical relationships between the different categories.

The core category in this study is discussed in the next section, but the model constructed details some specific conditions in the lives of the studied population that seems to give rise to the phenomenon of teenage pregnancy, revolving around one main theme: the belief that childbearing brings about a sense of achievement and self-fulfillment and that, far from being an unwanted occurrence of negative consequences as often cited in the literature, it is closely linked to local ideals of femininity, maturity, and small family sizes.

\section{Results}

In their own words: young mothers and their discourses about pregnancy

\section{- How does pregnancy "occur"? Motivations and unplanned consequences}

Retrospective accounts of life histories were, in this research, the only way of getting an insight into young women's intentions during their teens. Additionally, as Williams et al. 15 and Trussell et al. 16 note, when asked retrospectively about their fertility intentions, some women may report their feelings according to changes they have undergone in their lives, and declarations 
of wanted or unwantedness may correlate more closely with the outcomes of their pregnancies and current circumstances.

In the sample, only two girls said their pregnancies were planned as the result of a decision made jointly with their partners. However, from data collected in the focus group meetings and field notes, this decision was expressed as natural and expected from couples who were in longterm relationships, regardless of their age.

Data gathered shows the search for more freedom at home, i.e. from their patents, as a reason why one might want to get pregnant early in life. In addition to that, girls as young as $12-13$ years old are allegedly trying to become pregnant from drug lords or drug dealers, in an attempt to obtain financial help and enjoy high status among their peers. This is consistent with the findings in Cameron 17, Kenya 18, and South Africa 19, according to which the exchange of sex for gifts or financial support help shape young girls' sexual behavior, also favoring the non-use of condoms.

Most girls who became pregnant before age 18, however, had not planned the event, which happened soon after their first intercourse. According to them, the absence of contraceptive methods allied to their "naivety" at the time contributed to their early pregnancies. Such occurrence could also indicate insufficient knowledge on sexuality and reproduction.

\section{Knowledge and attitudes towards contraception}

Despite their broader knowledge of contraception and relative experience of using different types of methods, women who were 18 or older at the time of their first pregnancies surprisingly also reported them as unplanned. Such women had been in and out of relationships for years and had used different types of contraceptive methods, the pill being the most popular one. As in Brazil one does not need a prescription to purchase contraceptives over the counter, this is considered easy and preferred to queuing at the health center with other patients. Half of the girls who got pregnant in their early 20 s also mentioned they had been on the contraceptive pill when they became pregnant, thus being unable to understand how that happened. Possibly ill-use or simultaneous consumption of other medicines, such as antibiotics, added to the fact that over-the-counter drugs do not come with the doctor's recommendations. Perhaps, as Ajayi et al. 20 and Juarez ${ }^{21}$ point out, sporadic sex may help determine contraceptive choices. Young women might choose to interrupt the use of long-lasting contraception, such as the pill, in the absence of a stable relationship, thus becoming more exposed to unplanned pregnancies in the event of unprotected sex.

For the younger ones the lack of knowledge about reproduction could be seen in some cases and reinforced through contradictions that appeared in their discourses. This was true for most girls who got pregnant very early, showing insufficient or inadequate knowledge on the matter, including formal knowledge gained at school 20,22,23.

\section{- Embarrassment, moral barriers, and contraceptive choice}

Adapting the educational system to meet adolescents' needs could certainly improve their understanding of their own body and sexuality, but the question as to whether their real doubts are being clarified will remain unanswered for as long as teenage sexuality remains a taboo. None of the girls interviewed reported being able to talk about sex with their parents or older relatives, and $90 \%$ had never seen a gynecologist or talked to a reproductive health professional until they found out they were pregnant.

Reasons cited include embarrassment to see a gynecologist and lack of anonymity in the local health center. The center has a good varied team of health personnel and offers condoms, injectables, and pills as contraceptive methods. However, it does lack privacy, as everyone has to be screened by the social worker and explain their reasons for visiting. Additionally, health workers are normally people from that area, therefore acquainted with the girls who, in turn, fear the disclosure of their sex lives. Furthermore, some health clinics demand under-aged girls to come accompanied by their parents to prescribe free contraceptives, which could understandably be a barrier. Despite the different approach taken by the local health center, figures pointed out by the senior nurse show a timid demand proceeding from adolescents: for every one hundred patients she screens every day, only 2 or 3 adolescent girls would come every week in search of contraceptive methods. She states that the highest demand for pills comes from girls around the age of 23, who had already had a child and wanted to space births. Even so, she was looking at around 30 prescriptions per month, as opposed to the 900 (insufficient) condoms distributed monthly.

Table 1 shows the mothers' profiles and their chosen contraceptive methods before and after pregnancy: demand for hormonal contraceptives is slightly higher for girls over 21 despite their similar educational levels, showing perhaps not so much discrepancy in terms of formal 
Profile of the young mothers interviewed.

\begin{tabular}{lcc}
\hline Young mothers' profile & Under 18 at childbirth & Over 18 at childbirth \\
\hline Current age range & $18-24$ & $21-26$ \\
Incomplete primary school & 2 & 1 \\
Incomplete secondary school & 7 & 7 \\
Complete secondary school & 1 & 2 \\
University level (complete or incomplete) & 0 & Hormonal: 4 ; natural: 1 ; \\
Use of contraceptives at time of conception & condom: $2 ;$ none: 6 & condom: $3 ;$ none: 2 \\
Current use of contraception & IUD: 10 & IUD: 8 ; hormonal: 2 \\
\hline
\end{tabular}

knowledge gained at school, but probably less embarrassment to discuss their issues and gain access to certain methods.

Perhaps the most distinctive finding in this research was the fact that, unlike results found by some scholars, e.g. Manlove et al. 24 and Khan et al. 25, rapid subsequent births or the non-use of contraceptive methods after birth for teenagers who had not used a contraceptive method during their first sexual intercourse were not a visible concern in this sample. Thus the reluctance to use contraceptives is not associated with their unavailability or with the girl's lack of experience with different methods, since $90 \%$ of them opted for the IUD to space births and reduce the risk of another unplanned pregnancy once they had their first child. Perhaps this would help explain the low demand for other hormonal methods at the health center and raise the question as to whether or not the implementation of more family planning programs is the answer to tackle teenage pregnancy.

\section{Education and life plans}

Hoffert et al. ${ }^{26}$ refer to teenage pregnancy as one of the main contributors to young girls' discontinued education, obstructing their career paths and limiting their job prospects. Among the girls interviewed, truncated education is a common occurrence, but before making a premature association with early pregnancy, other factors regarding their background should be analyzed carefully. From the sample, the girls who got pregnant during their teens show almost the same educational level as the girls who got pregnant at a later stage in life, and despite their expressed desire to finish school and go to university, no one really tried to do so, even before they became pregnant.
Almeida et al. 27 found results that may partly resemble this reality when analyzing school trajectory and teenage pregnancy in three Brazilian state capitals, showing that despite the fact that young mothers had interrupted their studies, for many of them this decision was made before the onset of pregnancy. Similar results were found by Hof \& Richters 28 in Zimbabwe associating school interruption with existent financial problems prior to pregnancy.

Moreover economic hardship, especially in female-headed households, reinforces the need of getting a job at early ages in order to complement their family's income. As a result they have to juggle long working hours and evening classes, a combination that often proves unsuccessful. Some of the girls interviewed, for instance, had already been failing school for years before eventually dropping out.

In their research carried out in Brazil, Almeida \& Aquino 29 suggest that the risk of interruptions in education and dropping out of school under unfavorable family and social contexts may contribute to the acceptance of motherhood as the only possible successful path for impoverished girls. Saying they had interrupted their schooling because they got pregnant and had to provide for their babies only tells part of the story. However a child in this scenario can legitimate their choice and a decision that was imminent even before pregnancy occurred.

Jonhson-Hanks 30 draws attention to the need of understanding the place of schooling in girls' aspirations and analyzing it in conjunction with other sources of influence which are present in their social environment. It seems that in Vila Novo São Lucas education, however important, gives way to experiences that give the young mothers an immediate sense of fulfillment and achievement (i.e. having a child, a job, and a good work-life balance). 


\section{- Education and the job market}

Jobs that require little formal education (e.g. manicure, hairdressing, domestic work servant, etc) are a common source of income for many women in Vila Novo São Lucas.

Data on their working histories shows a preexistent financial need impelling girls to an early start in the job market, creating a feeling of economic stability, thus making education a laborious if unnecessary exercise, especially in the event of childbirth:

"I got pregnant when I was 14, but I've always worked, since the age of 11 (...) I thought that since I had a profession I could make money wherever I went, and my kids wouldn't starve. That was when I got pregnant again..." (L., 22 years old, first pregnant at age 14, mother to 2 children, hairdresser).

\section{- Motherhood}

Description of motherhood as an inevitable and desired occurrence was mentioned by $95 \%$ of the young mothers. Negative views on parenthood were absent and, differently from young girls' perception in South Africa 31 , were not viewed as compromising personal, professional, or financial aspirations. Whereas plans of educational attainment can be vague and dependent upon their financial situation, childbearing is an event that gives them a sense of purpose in life and a valid reason for their hard work that goes beyond money.

Responsibility is listed as the first and most important change motherhood had brought to their lives. However young those girls might appear to start raising a family, their discourses invariably highlight the fact that they went from "going out and having fun" to "being responsible and hard working" after childbirth, even though they all used to work to help their families prior to pregnancy.

The social environment and the roles of different actors

\section{- The family's reaction and their support}

The reaction of the family in face of unexpected pregnancies was one of surprise and sorrow. Mothers to teenage mothers reported being very upset when their daughters became pregnant and such reaction was also recollected by young women who got pregnant at age 23 , for example.

Ability to work and support themselves was reported by many girls as the reason why their parents were supportive of their pregnancies. Since most of them had already been working before their pregnancies and continued to do so, financial security ceased to be a concern for the parents, giving space to gradual demonstrations of fondness towards their pregnant daughters.

The family's support is extremely important for the young mothers, especially as many continue to live with their parents after birth. Young girls who do not have children mentioned their parents as their prime source of support in the event of an unplanned pregnancy, and every girl interviewed, despite their hesitation in telling their families at first, received unconditional support from them.

Their help goes from emotional to financial support, with women helping look after their grandchildren, giving the young mothers time to make a living and acquire the highly desired sense of responsibility.

The father's role and the decision to have a baby

In some cases pregnancy was planned, and since it was a joint decision, the couple stayed together to bear their child. Interpretation of the data gathered shows that such event often occurs in long-term relationships - nevertheless not very common in my sample - resulting in most participants continuing to live in their parents' house.

Pregnancies resulting from casual relationships were frequent, and girls' decision to have a baby was not strongly linked to the father's support, as they relied on their respective families.

\section{- A social phenomenon rather than isolated incidents}

The incident of teenage pregnancy in Vila Novo São Lucas is not considered a rare phenomenon by local people; likewise the naturalness of their speech regarding the subject may help to socially validate an event that became indisputably frequent. Despite the initial shock described by the mothers, the collectiveness of the event seems to lift the weight of having a teenage daughter who is pregnant.

Perhaps a collective understanding of teenage pregnancy as recurrent, nonetheless familiar, could help bring its occurrence to a level of social acceptance and support as it acquires a status of common phenomena. 


\section{Discussion}

Despite the fact that most teenage pregnancies were reported as unplanned, none was said to be unwanted, this being the most important finding and aim of this research, thus contradicting many studies on teenage pregnancy that fail to look at the girls' perspectives and subsequent influence on their behavior. The desire to become mothers acts as a drive to young girls and their decision not to use contraception is based on beliefs that motherhood will bring fulfillment and take them to a different level of maturity. For those in longterm relationships who actually decided to have a baby, their decision was based on their ideals of motherhood and life goals, and the fact that they were minors at the time did not weigh much in their decision.

The fact that very young girls were not using any contraception at the time they conceived was more related to lack of information about sexuality and reproduction, than to unavailability of contraceptive methods, since their local health center offers contraception for free. Teenagers reported lack of privacy as the major reason for not using their services, pointing to the inadequacy of family planning programs to adolescents' needs, and how this can be a major obstacle to their access in spite of their availability.

Gupta \& Leite 7 note that insufficient family planning services may contribute to high fertility rates amongst adolescents, especially if the services available are inadequate to their needs. In Vila Novo São Lucas some of the health providers believe they are offering good enough services to teenagers - despite being undistinguished from the ones offered to adult women - even though they do not seem to understand the low demand coming from adolescents. This study found that despite the presence of a local health center and free distribution of different types of contraceptive methods, the lack of anonymity and fear of disclosure of their sexual lives was an impediment to very young girls, as similarly found by Tangmunkongvorakul et al. 32 in Thailand. The fact that health providers lived in the neighborhood was seen as an obstacle to getting contraceptives from the center, reinforcing the paradox existent in contemporary Brazilian culture as proposed by Heilborn 8 , according to which, teenage sexuality is evident and socially tolerated, but in the form of "blaming the victim". Even though the girls showed knowledge about contraception, only the older ones who were already mothers would go to the health center to obtain it. Blanc \& Way 33 found similar results elsewhere in Latin America.
No negative health outcomes were related or associated with pregnancy at early ages, including those who had their first child at age 13. However, like Luke's 18 findings in Kenya, age and economic asymmetries between sex partners can play a role in exposing young girls to the consequences of unprotected sex i.e. STDs and HIV/ AIDS, in addition to unplanned pregnancies, since their partners are generally older, further contributing to power imbalances and girls' inability to negotiate contraceptive use 17,19. Focus group meetings also confirmed girls' apprehension to say "no" to their partners if asked to have unprotected sex, under fears of being accused of unfaithfulness.

Reluctance to use hormonal contraceptives was not based on assumptions of adverse side effects 9 , as emotional immaturity 34 was initially used to justify very young girls' pregnancies. However, throughout the process of data collection, it became clear that the lack of information about their sexuality and reproductive system was a major determinant of unplanned pregnancies, especially for 13-year-olds and those who became pregnant soon after their first intercourse. Dialogues about sex and contraception are inexistent within the family domain, and the formal knowledge acquired at school doubtfully covers all their queries 20,22,23,35.

Polit \& Kahn 36, Manlove et al. ${ }^{24}$, and Raneri \& Wiemman 37 mention subsequent fertility and high parity as a problem related to early motherhood, inhibiting career prospects for the mothers and helping perpetuate poverty. Such subsequent fertility was not present in the analyzed sample. On the contrary, only two girls deliberately decided to have one more child after giving birth in their teens, agreeing with their desired family size. For all the others, the decision to have the IUD implanted was made soon after childbirth However absent in the beginning of their sex lives, contraception was widely used to space births once the first child was born, showing no apparent reluctance to the use of modern contraceptive methods.

Although the problem of unwanted pregnancies is resolved by using the IUD, exposure to STDs and HIV/AIDS is not. Most of the participants got pregnant from casual partners, and another unplanned pregnancy seemed to be their biggest concern in not using condoms. High incidence of STDs, as portrayed by the local doctor, and the continuous practice of unprotected sex can pose a serious threat to sexually active adolescents and young adults 5 in Vila Novo São Lucas.

Obviously, there are other aspects of teenage pregnancy that were not covered by the scope of this study, such as sex work performed by street 
children in Brazil ${ }^{38}$. These marginalized teenagers possibly represent a significant proportion of unwanted or unplanned pregnancies, as well as STDs. Such cases, although distinguished from the ones covered by this study, also deserve further investigation.

One aspect worth mentioning is the fact that abortion is illegal in Brazil and can still be a major cause of death for young girls who do not have access to adequate treatment and attempt to abort by themselves, as shown by Alubo 39 and Almeida \& Aquino ${ }^{29}$, noting that in Brazil clandestine abortion clinics are not an option for economically underprivileged girls who, in turn, often have no option but to have the baby, though keeping fertility rates higher for poor teenagers as compared to teenagers of all social classes. Such discrepancy also deserves further investigation and could possibly point towards new teenage pregnancy rates across different social strata.

Early childbearing is seen as a major contributor to truncated education, and is believed to reduce career prospects for young women 26 . However, I found it hard to establish a direct causal relation between school dropout and pregnancy. Their financial reality and the very fact that girls had to start working quite early in life to help in the household income seems to have triggered the high levels of school failure previous to pregnancy, thus contributing to their gradual demotivation towards schooling. Heilborn et al. 8 found that, in another shantytown in Belo Horizonte, a high percentage of young females who experienced early pregnancy had already left school when the event happened. Although such occurrence was not clear in the sample, it is often ignored in studies on early childbearing. Pregnancy might not be the ultimate reason for school interruption, as other possible reasons can also discourage girls from attending classes, e.g. long working hours, and motherhood representing a more immediate successful activity when school does not. Qualitative data collection and in-depth analysis of their circumstances prior to and after childbirth can help explain the ulterior motives for quitting or not trying to return to school.

Finally, the ulterior motive for not using contraception and 'allowing' themselves to get pregnant seems to be the longstanding desire to become a mother, mentioned by $95 \%$ of the young mothers, and the sense of purpose and achievement associated with motherhood which corroborates Fustenberg Jr. 40, Almeida \& Aquino 29, and Bessa 12. In people's statements it becomes clear that working for one's children is more dignifying than working for oneself and having fun. Equally, the family's ambivalence in being initially upset over a pregnancy out of wedlock, but gradually supporting their daughters both financially and emotionally, indicates that, despite being recriminated, teenage pregnancy is related to Brazilian women's ideal of motherhood 8 and that, so far, these young parents have been following the traditional pattern of womanhood set out for them according to their local culture.

\section{Considerations}

The study shows that, for young Brazilian women, the ideal of motherhood and the sense of achievement it brings are a desired event in any woman's life, regardless of age. Despite their young age when giving birth for the first time, girls often mentioned the positive side of childbearing as a milestone in their lives, bringing responsibility and representing the beginning of adulthood. Pregnancy is thus seen as a desirable event that gives young mothers a purpose in life, and its social acceptance makes it legitimate - whether in or out of marriage - through parental support and the young woman's new role as mother.

Pregnancy and motherhood are far from being a problem for girls in Vila Novo São Lucas. For them the benefits outweigh the problems potentially associated with early childbearing, which is seen as life following its natural course.

Despite the great sense of achievement, pregnancy should not be the only avenue through which such girls can succeed. Financial strain pushes them to an early start in the job market, performing activities that require little education, making schooling an arduous and often unsuccessful task. Low educational attainment may result from poor living conditions for these girls, combined with limited prospects for pursuing further education and getting a better job.

The girls' knowledge about reproduction and sexuality could be improved if parent-child communication were more frequent and unrestricted. However, the intergenerational inability to approach these issues in the domestic sphere can make this a difficult target.

Alternatively, schools, mass media, and health workers could reach such girls in different spaces if programs were targeted to their specific needs and issues.

Improving the entire community's economic well-being seems to be the first necessary step by the government in order to deal with poor career prospects and subsequent poverty. Viewing teenage pregnancy as merely related to lack of contraception, resulting in truncated education and poor economic prospects, is a shortsighted perspective that overlooks the social environment legitimating motherhood. It also 
ignores the girls' own ambitions, which may not go much further than what they know their realities can provide. As their economic reality makes working more necessary than schooling, their horizons remain limited and are likely not to extend beyond motherhood.

\section{Resumo}

Este artigo apresenta os resultados de um estudo socioantropológico com mulheres de uma comunidade de baixa renda em Belo Horizonte, Minas Gerais, Brasil. Usando métodos qualitativos, analisa a gravidez pela perspectiva das jovens mães e a contribuição de seu ambiente socioeconômico. Mostra o papel de diferentes atores nas decisões reprodutivas e identifica normas culturais contraditórias que recriminam práticas sexuais na adolescência, mas vê a maternidade como ritual de passagem para a vida adulta. Com base em críticas sobre a insuficiência de programas de planejamento familiar e das consequências para sua saúde e futuro econômico, este artigo argumenta que a maternidade é uma atividade bem sucedida por meio da qual essas jovens preenchem o ideal coletivamente reconhecido de se tornar mulher, além de carregar um senso de realização num ambiente onde a falta de oportunidades prevalece antes mesmo da ocorrência de uma gravidez. Adequação na instrução formal e melhores perspectivas econômicas são possiveis soluções para provê-las com metas que vão além da maternidade, porém dentro dos limites de sua realidade econômica.

Gravidez na Adolescência; Anticoncepção; Planejamento Familiar

\section{Acknowledgments}

The author wishes to thank the University College London Masters Fieldwork Bursary for the financial support. 


\section{References}

1. Wulf D, Singh S. Sexual activity, union and childbearing among adolescent women in the Americas. Int Fam Plann Perspect 1991; 17:137-44.

2. Taniguchi H. The timing of childbearing and women's wages. J Marriage Fam 1999; 61:1008-101.

3. Butler A. The changing economic consequences of teenage childbearing. Soc Serv Rev 1992; 66:1-31.

4. Bearinger LH, Sieving RE, Ferguson J, Sharma V. Global perspectives on the sexual and reproductive health of adolescents: patterns, prevention and potential. Lancet 2007; 369:1120-3.

5. Zabin LS, Kiragu K. The health consequences of adolescent sexual and fertility behavior in SubSaharan Africa. Stud Fam Plann 1998; 29:210-32.

6. Bongaarts J, Bruce J. The causes of unmet need for contraception and the social content of services. Stud Fam Plann 1995; 26:57-75.

7. Gupta N, Leite IC. Adolescent fertility behaviour: trends and determinants in Northeast Brazil. Int Fam Plann Perspect 1999; 25:125-30.

8. Heilborn ML, Brandão ER, Cabral CS. Teenage pregnancy and moral panic in Brazil. Cult Health Sex 2007; 9:403-14.

9. Castle S. Factors influencing young Malians' reluctance to use hormonal contraceptives. Stud Fam Plann 2003; 34:186-99.

10. Agadjanian V. Men's talk about “women's matters": gender, communication, and contraception in urban Mozambique. Gender \& Society 2002; 16:194-215.

11. Alves JED, Cavenaghi S. Timing of childbearing in below replacement fertility regimes: how and why Brazil is different. In: Annals of the XXVI International Population Conference IUSSP. http://www. iussp.org/marrakech2009/index.php (accessed on 14/Jan/2010)

12. Bessa GH. Between "modern women" and "woman-mothers": reproduction and gender identity among low-income Brazilian women. East Lansing: International Studies and Programs, Michigan State University; 2004. (Women \& International Development Working Paper, 283).

13. Portal BH. Histórico da Vila Novo São Lucas. http://portalpbh.pbh.gov.br/pbh/ecp/comunida de.do? evento $=$ portlet $\&$ pIdPlc $=$ ecpTaxonomiaMe nuPortal\&app $=$ urbel\&tax $=8173 \& l a n g=$ pt_BR\&pg $=$ $5580 \&$ taxp $=0$ \&idConteudo $=31621 \&$ chPlc $=31621$ (accessed on 06/Apr/2010).

14. Borgatti S. Introduction to grounded theory. http://www.analytictech.com/mb870/introtoGT. $\mathrm{htm}$ (accessed on 08/Jan/2010).

15. Williams L, Abma J, Piccinino LJ. The correspondence between intention to avoid childbearing and subsequent fertility: a prospective analysis. Fam Plann Perspect 1999; 31:220-7.

16. Trussel J, Vaughan B, Stanford J. Are all contraceptive failures unintended pregnancies? Evidence from the 1995 National Survey of Family Growth. Fam Plann Perspect 1999; 31:246-60.

17. Hattori MK, DeRose L. Young women's perceived ability to refuse sex in urban Cameron. Stud Fam Plann 2008; 39:309-20.
18. Luke N. Confronting the "sugar daddy" stereotype: age and economic asymmetries and risky sexual behaviour in urban Kenya. Int Fam Plann Perspect 2005; 31:6-14.

19. Kaufman CE, Stavrou SE. "Bus fare please": the economics of sex and gifts among young people in urban South Africa. Cult Health Sex 2004; 6:377-91.

20. Ajayi AA, Marangu LT, Miller J, Paxman JM. Adolescent sexuality and fertility in Kenya: a survey of knowledge, perceptions and practices. Stud Fam Plann 1991; 22:205-16.

21. Juarez FM. Partnership dynamics and sexual health risk among male adolescents in the favelas of Recife, Brazil. Int Fam Plann Perspect 2006; 32:62-70.

22. Costa COM, Pinho JFC, Martins SJ. Aspectos psicossociais e sexuais de gestantes adolescentes em Belém-Pará. J Pediatr (Rio J.) 1995, 71:151-7.

23. Gage AJ. Sexual activity and contraceptive use: the components of the decision-making process. Stud Fam Plann 1998; 29:154-66.

24. Manlove J, Mariner C, Papillo AR. Subsequent fertility among teen mothers: longitudinal analysis of recent national data. J Marriage Fam 2000; 62: 430-48.

25. Khan JR, Rindfuss RR, Guilkey DK. Adolescent contraceptive method choices. Demography 1990; 27:323-35.

26. Hoffert SL, Reid L, Mott FL. The effects of early childbearing on schooling over time. Fam Plann Perspect 2001; 33:259-67.

27. Almeida MCC, Aquino EML, Barros AP. School trajectory and teenage pregnancy in three Brazilian state capitals. Cad Saúde Pública 2006; 22: 1397-409.

28. Hof C, Richters A. Exploring intersections between teenage pregnancy and gender violence: lessons from Zimbabwe. Afr J Reprod Health 1999, 3:51-65.

29. Almeida MCC, Aquino EML. The role of education level in the intergenerational pattern of adolescent pregnancy in Brazil. Int Perspect Sex Reprod Health 2009; 35:139-46.

30. Johnson-Hanks J. Education, ethnicity, and reproductive practice in Cameroon. Population-E 2003; 58:153-80.

31. Varga C. How gender roles influence sexual and reproductive health among South African adolescents. Stud Fam Plann 2003; 34:160-72.

32. Tangmunkongvorakul A, Kane R, Wellings K. Gender double standards in young people attending sexual health services in Northern Thailand. Cult Health Sex 2005; 7:361-73.

33. Blanc AK, Way AA. Sexual behaviour and contraceptive knowledge and use among adolescents in developing countries. Stud Fam Plann 1998; 29:106-16.

34. Dixon-Mueler R. How young is "too young"? Comparative perspectives on adolescent sexual, marital, and reproductive transitions. Stud Fam Plann 2008; 39:247-62.

35. Hindin M, Fatus AO. Adolescent sexual and reproductive health in developing countries: an overview of trends and interventions. Int Perspect Sex Reprod Health 2009; 35:58-62. 
36. Polit DF, Kahn JR. Early subsequent pregnancy among economically disadvantaged teenage mothers. Am J Public Health 1986; 76:167-71.

37. Raneri LG, Wiemann CM. Social ecological predictors of repeat adolescent pregnancy. Perspect Sex Reprod Health 2007; 39:39-47.

38. Dowsett GW. Some considerations on sexuality and gender in the context of AIDS. Reprod Health Matters 2003; 11:21-9.
39. Alubo O. Adolescent reproductive health practices in Nigeria. Afr J Reprod Health 2001; 5:109-19.

40. Fustenberg Jr. FF. When will teenage childbearing become a problem? The implications of Western experience for developing countries. Stud Fam Plann 1998; 29:246-53.

Submitted on $21 / \mathrm{Jul} / 2011$

Final version resubmitted on 22/Nov/2011 Approved on 14/Dec/2011 